\title{
Analisis Penerapan Metode 5S pada Warehouse Fast Moving PT. Indonesia Power UBP Mrica Kabupaten Banjarnegara
}

\author{
Nadiya Pramudian K.*) dan Novie Susanto \\ Departemen Teknik Industri, Fakultas Teknik, Universitas Diponegoro \\ Jl. Prof. H. Soedarto, SH, Semarang, 50275, Indonesia
}

DOI: 10.20961/performa.18.1.19078

\begin{abstract}
Abstrak
PT. Indonesia Power UBP Mrica Kabupaten Banjarnegara adalah perusahaan yang bergerak adalah bidang penyediaan dan distribusi listrik. Untuk perusahaan yang khusus bergerak di bidang penyediaan dan distribusi listrik, perusahaan memiliki tempat untuk menyimpan barang dan suku cadang untuk produksi, biasanya disebut gudang. Selain sebagai tempat untuk menyimpan barang, gudang juga dapat berfungsi sebagai penyimpanan sementara untuk produk atau suku cadang yang akan digunakan dan didistribusikan, baik kepada konsumen atau gudang lainnya. Tujuan utama dari penelitian ini adalah untuk mengetahui bagaimana metode 5S diterapkan di gudang PT. Indonesia Power UBP Mrica. Implementasi di sini termasuk pelabelan rak dan kabinet dan juga standarisasi untuk seluruh kegiatan di gudang demi mengoptimalkan kinerja di gudang. Hasil penelitian ini akan menjadi saran perbaikan terkait dengan kinerja gudang.
\end{abstract}

Kata kunci: 5S, gudang, seiri, seiton, seiso, seiketsu, shitsuke

\begin{abstract}
Indonesia Power UBP Mrica ltd. in the Banjarnegara district is a company that runs is the field of provision and distribution of electricity. For a company that specialized in the field of provision and distribution of electricity it is vital to have a place to store items and spare parts for production, usually called warehouse. Beside for a place to store stuff, a warehouse can also function as a temporary storage for products or spare parts that will be used and distributed, either to the consumers or the other warehouses. The main goal of this study is to know how the 5S method is implemented in the warehouse of Indonesia Power UBP Mrica ltd. Implementation here include the labelling of shelf and cabinet, and also the standardization for the whole activities in the warehouse for the sake of optimizing performance in the warehouse. The result of this research will be a suggestion of refinement related to the warehouse performance.
\end{abstract}

Keywords: 5S, warehouse, seiri, seiton, seiso, seiketsu, shitsuke

\section{Pendahuluan}

Pada era globalisasi sekarang ini banyak bermunculan perusahaan-perusahaan yang mempunyai kemampuan dalam bersaing di pasar industri. Perusahaan yang mampu bersaing di pasar industri maka perusahaan tersebut akan memperoleh berbagai macam keuntungan, baik kecil maupun besar. Hal tersebut mendorong berbagai perusahaan untuk mengembangkan strategi yang digunakannya agar dapat bersaing didalamnya. Seiring dengan perkembangan dunia industri di Indonesia diikuti dengan persaingan pasar yang semakin meningkat, menuntut para pelaku pasar industri untuk meningkatkan efisiensi di segala bidang.

Dalam suatu perusahaan yang bergerak di bidang penyedia dan pendistribusian sebuah energi listrik, selalu dibutuhkan suatu tempat penyimpanan barang-barang dan sparepart untuk produksi, atau yang disebut warehouse. Selain berfungsi sebagai tempat penyimpanan barang, warehouse dapat pula berfungsi sebagai tempat penyimpanan sementara produk atau sparepart yang nantinya akan diapakai dan didistribusikan, baik ke konsumen atau warehouse lainnya.

Fast Moving Warehouse pada PT Indonesia Power UBP Mrica yang terletak di Kabupaten Banjarnegara memiliki luas 16x16 m2. Walaupun warehouse pada PT Indonesia Power UBP Mrica sudah memiliki fungsi yang jelas, namun masih terdapat berbagai jenis barang lain yang tidak sesuai dengan fungsi warehouse, seperti barang yang sudah rusak/tidak layak dipakai, belum teridentifikasinya barang sisa produksi yang berserakan di lantai dan banyak barang yang belum sesuai pada tempatnya. Selain itu, terdapat pula banyak rak dan lemari yang masih kosong, sehingga barang-barang yang ada di dalam warehouse tidak disimpan secara optimal. Permasalahan lain yang terdapat di dalam warehouse adalah belum optimalnya 
pengkasifikasian secara baik terhadap barang-barang yang ada di dalam warehouse. Oleh karena itu, dibutuhkan suatu metode khusus dalam mengoptimalkan fungsi warehouse.

Salah satu metode yang kerap kali digunakan untuk mengoptimalkan proses penyimpanan warehouse adalah metode 5S, yaitu Seiri, Seiton, Seiso, Seiketsu, dan Shitsuke. Dengan metode 5S, diharapkan suatu warehouse dapat memiliki suatu kerja standar dengan kualitas terbaik. Metode 5S juga diharapkan menjadi kebiasaan dan kesadaran para pekerja dalam melakukan pekerjaanya.

Penerapan metode 5S pada warehouse PT Indonesia Power belum berjalan dengan optimal. Penerapan hanya dilakukan apabila sedang dilaksanakanya bulan K3 nasional setahun sekali. Pelaksanaanya meliputi adanya lomba 5S antar divisi. Kurangnya kesadaran antar pekerja tentang budaya menyebabkan terhambatnya proses pelestarian budaya $5 \mathrm{~S}$ itu sendiri.

\section{Tinjauan Pustaka}

Menurut Mulcahy dalam Ekoanindiyo dan Wedana (2012) pengertian gudang adalah sebuah fungsi penyimpanan berbagai macam jenis produk yang memiliki unit-unit penyimpanan dalam jumlah kecil atau besar dalam jangka waktu saat produk dihasilkan oleh pabrik (penjual) dan saat produk dibutuhkan oleh pelanggan atau stasiun kerja dalam fasilitas pembuatan.

Menurut Wignjosoebroto (2012) terdapat beberapa tujuan utama gudang yang berkaitan dengan pengadaan barang, yaitu sebagai berikut :

1. Pengawasan, sistem administrasi yang baik dapat mengontrol keluar masuknya material atau peredaan material. Tugas ini menyangkut keamanan dan material, yaitu jangan sampai hilang.

2. Pemilihan, yaitu aktifitas pemeliharaan agar material yang disimpan di dalam gudang tidak cepat rusak dalam penyimpanan.

3. Penimbunan penyimpanan, yaitu agar sewaktu-waktu diperlukan maka material yang dibutuhkan akan tetap tersedia sebelum dan selama proses berlangsung.

4. Perencanaan tata letak mesin dan departemen dalam pabrik.

\section{Konsep 5S}

Menurut Chen (2008) tahapan-tahapan dalam 5S yaitu sebagai berikut:

1. Sort (Seiri), mencakup pemilihan konten dalam tempat kerja dan membuang item yang tidak perlu.

2. Straighten (Seiton), mencakup menempatkan item yang dibutuhkan pada tempatnya dan menyediakan kemudahan akses

3. Shine (Seiso), mencakup membersihkan tempat kerja, menjaga kebersihan sehari-hari, dan menggunakan pembersih untuk mengecek tempat kerja dan peralatan yang bisa cacat

4. Standardize (Seiketsu), mencakup membuat kontrol visual dan panduan untuk menjaga tempat kerja tetap tertata, teratur, dan bersih

5. Sustain (Shitsuke), mencakup pelatihan dan disiplin untuk memastikan semua orang mengikuti standar 5S

\section{Metodologi Penelitian}

Penelitian dilakukan di bagian Warehouse PT Indonesia Power UBP Mrica Kabupaten Banjarnegara mulai tanggal 3 Januari 2017 sampai dengan 31 Januari 2017. Metode pengumpulan data yang digunakan dalam penelitian ini yaitu pertama studi pustaka, penulis melakukan studi pustaka berupa membaca referensireferensi ilmiah yang berkaitan dengan topik yang dibahas untuk kemudian dijadikan sebagai landasan teori dalam pemecahan masalah. Topik yang dibahas yaitu penerapan budaya 5S pada warehouse PT.Indonesia Power UBP Mrica. Selanjutnya melakukan studi lapangan, studi lapangan yang dilakukan berupa pengamatan langsung di gudang PT.Indonesia Power UBP Mrica kabupaten Banjarnegara. Studi lapangan berguna untuk mencari data tentang masalah pada perusahaan yang nantinya akan dianalisis dan diberikan saran perbaikan.Tahap terahir wawancara, wawancara dilakukan kepada karyawan yang bertanggung jawab mengelola gudang PT.Indonesia Power UBP Mrica kabupaten Banjarnegara yaitu dengan Bapak Purwo yang berusia 40 tahun. dan Kepala Bagian K3 yaitu Bapak Andri Ramdhan Cahya. Wawancara berguna untuk mencari data tentang masalah pada perusahaan yang nantinya akan dianalisis dan diberikan saran perbaikan. Data yang diperoleh seperti data barang-barang yang disimpan di gudang, data mengenai pengelolaan gudang, data profil perusahaan, data proses produksi perusahaan dan data mengenai pekerja gudang PT Indonesia Power. 


\section{Hasil dan Pembahasan}

\section{Tinjauan Lapangan}

Aktivitas pergudangan Fast Moving Ware house pada PT Indonesia Power cukup kompleks dan belum efisien. Terdapat kesulitan bagi pekerja warehouse ketika terdapat letak penyimpanan barang yang belum sesuai dengan letaknya sehingga menyulitkan pekerja warehouse. Banyak barang -barang sisa produksi tergeletak dilantai dan belum teridentifikasi sehingga menyulitkan mobilitas pekerja.

\section{Permasalahan yang timbul}

Dengan diterapkannya metode pekerjaan yang masih manual, terdapat beberapa kekurangan yang terjadi pada warehouse. Seluruh barang yang terdapat pada warehouse belum semuanya dikelompokkan dengan baik di tempat penyimpanan barang. Belum teridentifikasinya barang-barang sisa produksi dengan baik yang banyak tergeletak di lantai dan berada didepan pintu warehouse sehingga menyebabkan mobilitas pegawai terganggu. Selain itu, kekurangan terdapat pada rak penyimpanan barang. Terdapat beberapa rak atau lemari yang masih kosong atau tidak digunakan.

Pada warehouse terdapat pula jenis barang yang tidak sesuai dengan fungsi warehouse, seperti, spons sisa, plastik bekas, kardus dll. Terdapat pula beberapa jenis barang yang sudah lama dan tidak terpakai, namun masih disimpan dan mengeletak dilantai. Oleh karena itu, diusulkan penerapan Metode 5S pada warehouse PT Indonesia Power UBP Mrica. Salah satu metode yang kerap kali digunakan untuk mengoptimalkan proses penyimpanan warehouse adalah metode 5S, yaitu Seiri, Seiton, Seiso, Seiketsu, dan Shitsuke. Dengan metode 5S, diharapkan suatu warehouse dapat memiliki suatu kerja standar dengan kualitas terbaik. Metode 5S juga diharapkan menjadi kebiasaan dan kesadaran para pekerja dalam melakukan pekerjaanya.

\section{Evaluasi Budaya 5S}

\section{Seiri (Sort / Ringkas / Pemilahan)}

Tujuan dari perancangan seiri ini adalah mengeluarkan barang-barang yang tidak diperlukan atau masih belum dibutuhkan ke dalam area tempat penyimpanan sementara. Pada Fast Moving Warehouse PT Indonesia Power, masih terdapat barang-barang yang tidak sesuai dengan fungsi warehouse dan masih banyak barangbarang sisa produksi tergeletak dibawah atau dilantai. Barang-barang yang tergeletak di lantai masih banyak yang belum teridentifikasi dengan pasti termasuk golongan apakah barang tersebut. Masih banyak barang yang tidak terpakai yang seharusnya tidak berada di warehouse sepeti spons bekas, kardus bekas, dan plastik bekas. Hal ini berarti konsep Seiri belum diaplikasikan secara optimal pada Fast Moving Warehouse.
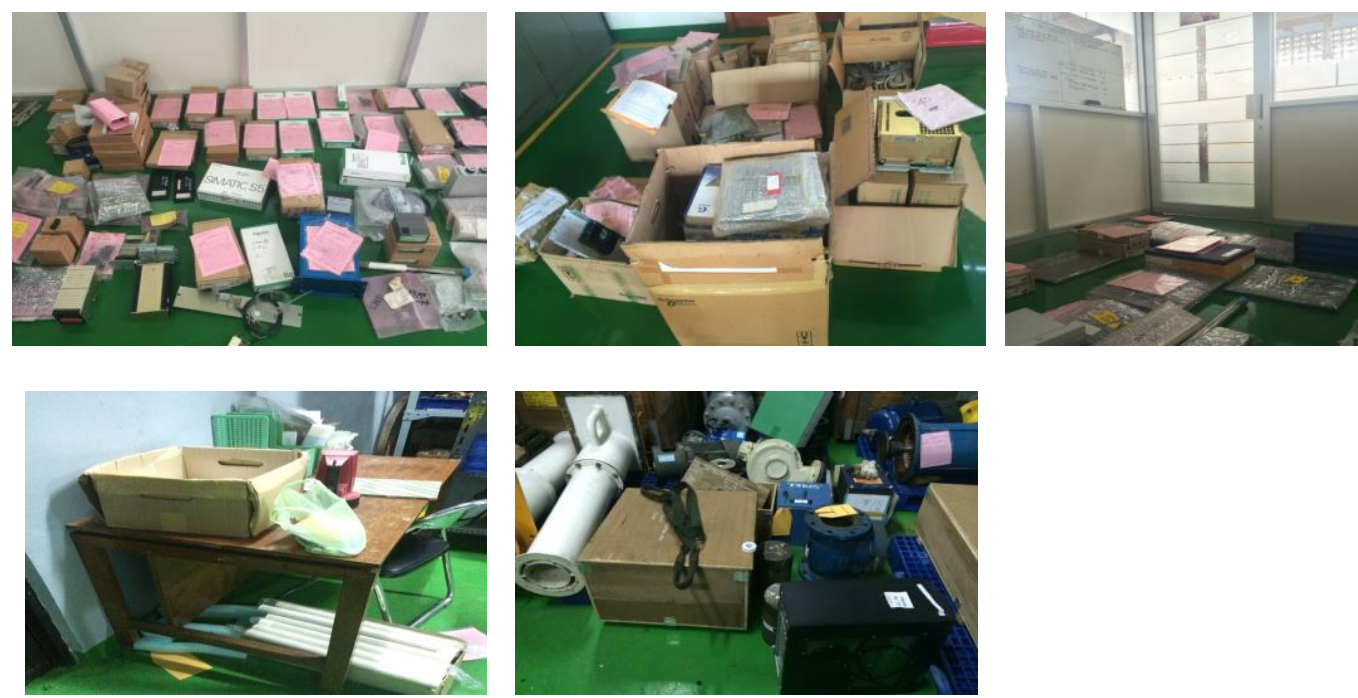

Gambar 1. Barang yang Belum Teridentifikasi

\section{Seiton (Set in Order / Rapi / Penataan)}

Tujuan perancangan adalah untuk mempermudah dalam pencarian barang, mengambil dan mengembalikan alat yang dibutuhkan. Pada Fast Moving PT Indonesia Power, konsep Seiton belum diterapkan dengan baik. Hal tersebut dapat dilihat dari banyaknya barang-barang yang terdapat pada warehouse yang tidak tertata dengan rapi. Seperti adanya beberapa dokumen yang seharusnya dikelompokan menjadi satu arsip file, diletakan rapi di dalam lemari dan diberikan label nama arsip. 


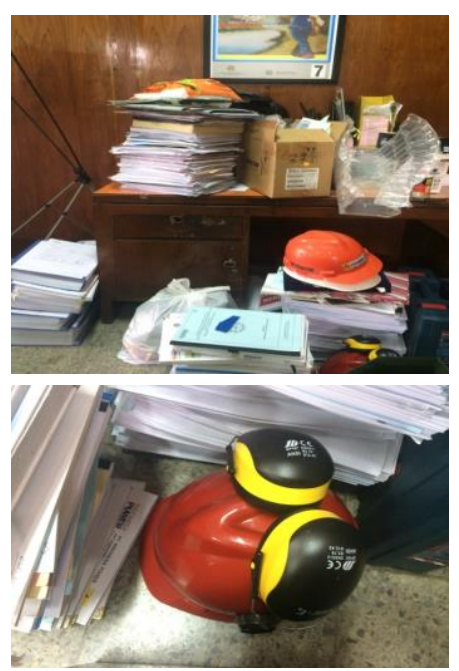

Gambar 2. Barang dan File yang Berantakan

3. Seiso (Shine / Resik / Pembersihan)

Tugas dan kebersihan bukan hanya dilaksanakan bagian kebersihan saja narnun menjadi tugas dan tanggung jawab bersama di area gudang. Tujuan dari resik, membuat tempat kerja menjadi bersih dan nyaman bagi pekerja yang sedang melaksakan tugasnya.

Pada Fast Moving Warehouse, konsep Seiso belum diterapkan dengan baik. Pembersihan tidak dilakukan secara berkala, sehingga banyak sekali debu pada lantai dan rak, sehingga mengotori barang-barang pada warehouse.

\section{Seiketsu (Standardize / Rawat / Pemantapan)}

Tujuan dari aktivitas ini yaitu kegiatan pemilahan, penataan, dan pembersihan yang telah dilakukan tetap terlaksana secara berkesinambungan. Konsep Seiketsu belum diterapkan pada Fast Moving Warehouse. Belum adanya standardiasi yang pasti, membuat Fast Moving Warehouse masih memiliki banyak kekurangan seperti yang telah disebutkan sebelumnya.

5. Shitsuke (Sustain / Rajin / Pembiasaan)

Aktivitas ini bertujuan untuk membiasakan budaya 5S sebagai upaya untuk menciptakanlingkungan kerja yang lebih baik. Pada Fast Moving Warehouse, memang sudah ada program pelatihan 5S bagi pekerja warehouse seperti adanya lomba cerdas cermat $\mathrm{K} 3$, Lomba $5 \mathrm{~S}$, dan seminar yang melingkupi 5S namun untuk kesadaran dari setiap pegawai kurang untuk selalu menjaga kebersihan, kerapian dari tempat kerja selain memang untuk petugas kebersihan itu sendiri, sehingga pekerja warehouse belum dapat menerapkan 5S pada warehouse secara optimal.

\section{Usulan Perbaikan}

Berdasarkan evaluasi penerapan 5S pada warehouse PT Indonesi Power UBP Mrica yang telah dibahas pada sub sebelumnya, dapat diketahui bahwa budaya $5 \mathrm{~S}$ belum diterapkan secara optimal. Untuk itu diperlukan beberapa usulan, yaitu sebagai berikut :

1. Seiri (Sort / Ringkas / Pemilahan)

a. Memilih barang sesuai dengan kriteria barang

b. Mengumpulkan data barang dan alat kerja

c. Menetukan tindakan terhadap masing-masing barang

2. Seiton (Set in Order / Rapi / Penataan)

Pelaksanaan aktivitas ini pada warehouse PT. Indonesia Power belum optimal pelaksanaanya. Langkahlangkah yang dapat dilakukan :

a. Barang-barang yang memiliki frekuensi pemakaian yang sama dikelompokan dalam suatu lokasi seperti batu battery, lampu, cat, lem, mur baut dapat berupa rak atau lemari penyimpanan. Adapun maksud dari langkah ini adalah agar memudahkan pencarian barang lewat suatu pengkelompokan.

b. Barang-barang yang telah dikelompokan dapat diberi label atau papan nama. Dengan begitu, pencarian barang dapat menjadi lebih cepat dan efisien. Metode pemberian label atau katu nama tidak dilakukan manual namun seharusnya memakain sofware pelabelan, sehinggan lebih efisien dan efektif.

3. Seiso (Shine / Resik / Pembersihan)

Penerapan langkah ini belum diterapkan dengan baik pada warehouse PT Indonesia Power UBP Mrica. Adapun penerapan langkah-langkah Seiso adalah sebagai berikut : 
a. Mendata alat-alat kebersihan yang berfungsi dan akan dipakai di warehouse PT.Indonesia Power UBP Mrica seperti alat pembersih yaitu sapu, lap pel, kemoceng dan pengki.

b. Menetukan kriteria kebersihan

c. Penerapan metode resik, yaitu menggunakan metode 5S. Program dilaksanakan setiap hari, dilakukan setiap awal masuk dan sebelum pulang.

\section{Seiketsu (Standardize / Rawat / Pemantapan)}

Penerapan tahapan ini pada warehouse PT.Indonesia Power belum terlaksana. Usulan yang diberikan pada proses ini yaitu :

Membuat standarisasi mengenai batasan aktivitas pada warehouse. Peraturan ini dapat berupa kontrol visual seperti larangan tidak merokok, larangan membuang sampah sembarangan, dan kewajiban menggunakan alat pelindung diri selama berada di lingkungan warehouse. Berikut ini beberapa peringatan yang dapat digunakan di dalam warehouse:
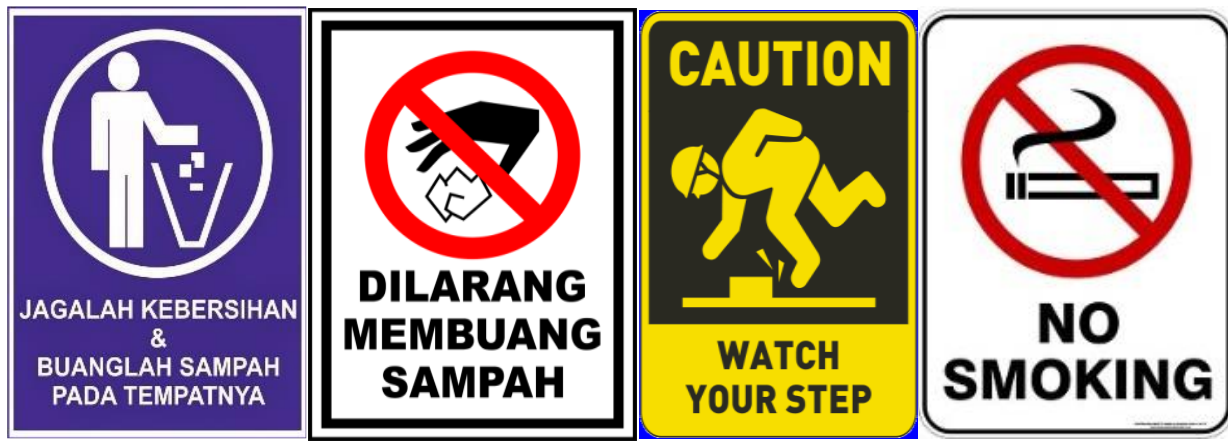

Gambar 3. Rambu-Rambu Peringatan

Melakukan inspeksi harian atau mingguan oleh pihak manajemen. Inspeksi dilakukan secara mendadak pada harian tertentu, baik untuk mengetahui perkembangan yang dicapai, mempertahankan konsistensi, atau melakukan perbaikan.Manajemen dapat memberikan perhitungan penalti kepada pekerja warehouse berdasarkan temuan kesalahan, sebagai contoh:

a. Emas apabila jumlah temuan 3 atau dibawah 3.

b. Perak apabila jumlah temuan 4 sampai 5 .

c. Hijau apabila jumlah temuan 6 sampai 8 .

d. Merah apabila jumlah temuan 9 sampai 10.

e. Hitam apabila jumlah temuan di atas 10 .

Atas peritungan penalty, manajemen dapat memberikan reward dan punishment. Reward dapat diberikan berupa intensif.

5. Shitsuke (Sustain / Rajin / Pembiasaan)

Pada warehouse PT.Indonesia Power UBP Mrica, tahapan ini belum terlaksana. Usulan perbaikan terhadap tahapan ini yaitu:

a. Melakukan audit secara berkala mengenai perkembangan penerapan 5S. Audit dilakukan dengan cara pengamatan secara langsung oleh tim audit yang independen.

c. Melakukan sosialisasi kepada pekerja warehouse PT.Indonesia Power UBP Mrica mengenai pentingnya penerapan $5 \mathrm{~S}$

d. Melaksanakan kegiatan "15 Menit 5S" bertujuan untuk membantu menanamkan budaya 5S dalam aktivitas kerja seharihari.

\section{Kesimpulan}

Penerapan metode 5S pada warehouse PT Indonesia Power belum berjalan dengan optimal. Penerapan hanya dilakukan apabila sedang dilaksanaknaya bulan K3 nasional setahun sekali. Oleh karena itu masih banyak sekali kekurangan yang terdapat pada warehouse PT Indonesia Power UBP Mrica.

Usulan perbaikan yang diberikan adalah untuk menerapkan 5S sesering mungkin, memberikan saran untuk selalu memiliki kesadaran akan pentingnya budaya 5S kapan saja dan dimana saja pada saat bekerja, agar proses aktivitas pada warehouse PT Indonesia Power UBP Mrica lebih optimal dan efisien. Pada tahap Seiri, diusulkan untuk memilah barang yang sesuai dan tidak sesuai dengan warehouse. Pada tahapan Seiton diusulkan pemberian label pada rak dan lemari penyimpanan agar proses pencarian barang lebih efisien. Pada tahap seiso, diusulkan semua pekerja yang terlibat dengan warehouse harus bertanggung jawab atas kebersihan warehouse, serta penerapan metode resik. Pada tahapan Seiketsu, diusulkan untuk dibuat 
standarisasi, serta sistem reward dan punishment selama berjalanya aktivitas. Sedangkan pada tahap Shitsuke, diusulkan untuk adanya tim audit untuk mengaudit penerapan 5S pada warehouse PT Indonesia Power UBP Mrica.

\section{Daftar Pustaka}

Chen, Lixia Meng Bo, 2008, How to Make 5S as a Culture in Chines Enterprise, International Conference on Information Management, Innovation Management and Industrial Engineering, pp 221-224.

Ekoanindyo, F.A. dan Wedana, Y.A., 2012, Perencanaan Tata Letak Gudang Menggunakan Metode Shared Storage di Pabrik Plastik Kota Semarang, Dinamika Teknik, Vol. VI, No. 1, Januari 2012, pp $46-57$

Hartono,Gunawarman. 2008. Implementasi Prinsip Kerja 5s Pada Bagian Pabrikasi I Untuk Meningkatkan Efisiensi Waktu Produksi.Jakarta :Inasea.

Hirano, Hiroyuki. 1996. Penerapan 5S Di Tempat Kerja: Pendekatan LangkahLangkah Praktis. Jakarta: Penerbit PT Temprint.

Lamprea, E.J.H., Carreno, Z.M.C., dan Sanchez, P.M.T.M., 2015, Impact of 5S on Productivity, Quality, Organizational Climate and Industrial Safety in Caucho Metal Ltda., Vol. 23, No. 1, pp 107-117.

Rimawan, Erry. 2012. Analisa Penerapan 5s dan Safety Pada Areawarehouse Di Pt. Multifilling Mitra ndonesia. Jakarta : Jurnal Ilmiah PASTI Volume VI Edisi 1 - ISSN 2085-5869.

Srinivasan, Siddarth. 2012. The Impact Of 5 s On The Safety Climate Of Manufacturing Workers. Louisiana:Louisiana State University.

Suwondo, Chandra. 2012.Penerapan Budaya Kerja Unggulan 5s (Seiri, Seiton, Seiso, Seiketsu, Dan Shitsuke) Di Indonesia. Jakarta : Jurnal Magister Managemen Asmi

Widanti, Tri. 2015. Implementasi 5 S untuk Optimasi Keselamatan,Kesehatan, dan Performa Kerja.Tangerang : Pusat Teknologi Limbah Radioaktif Badan Tenaga Nuklir Nasional.

Wiratmani, Elfitria. 2013. Analisis Implementasi Metode 5s Untuk Pemeliharaan Stasiun Kerja Proses Silk Printing Di Pt. Mandom Indonesia Tbk. Jakarta: Universitas Indraprasta PGRI 